\title{
Defective erythroid differentiation in miR-451 mutant mice mediated by $14-3-3 \zeta$
}

\section{David M. Patrick, ${ }^{1}$ Cheng C. Zhang, ${ }^{2,3}$ Ye Tao, ${ }^{4}$ Huiyu Yao, ${ }^{5}$ Xiaoxia Qi, ${ }^{1}$ Robert J. Schwartz, ${ }^{6,7}$ Lily Jun-Shen Huang, ${ }^{5}$ and Eric N. Olson ${ }^{1,8}$}

${ }^{1}$ Department of Molecular Biology, University of Texas Southwestern Medical Center, Dallas, Texas 75390, USA; ${ }^{2}$ Department of Physiology, University of Texas Southwestern Medical Center, Dallas, Texas 75390, USA; ${ }^{3}$ Department of Developmental Biology, University of Texas Southwestern Medical Center, Dallas, Texas 75390, USA; ${ }^{4}$ Institute of Biosciences and Technology, Texas A\&M Health Science Center, Houston, Texas 77030, USA; ${ }^{5}$ Department of Cell Biology, University of Texas Southwestern Medical Center, Dallas, Texas 75390, USA; ${ }^{6}$ Texas Heart Institute, Texas Medical Center, Houston, Texas 77030, USA; ${ }^{7}$ Department of Biology and Biochemistry, The University of Houston, Houston, Texas 77004, USA

Erythrocyte formation occurs throughout life in response to cytokine signaling. We show that microRNA-451 (miR451) regulates erythropoiesis in vivo. Mice lacking miR-451 display a reduction in hematrocrit, an erythroid differentiation defect, and ineffective erythropoiesis in response to oxidative stress. 14-3-3 $\zeta$, an intracellular regulator of cytokine signaling that is repressed by miR-451, is upregulated in $\mathrm{miR}-451^{-/-}$erythroblasts, and inhibition of 14-3-3 $\zeta$ rescues their differentiation defect. These findings reveal an essential role of $14-3-3 \zeta$ as a mediator of the proerythroid differentiation actions of miR-451, and highlight the therapeutic potential of miR-451 inhibitors.

Supplemental material is available at http://www.genesdev.org.

Received April 28, 2010; revised version accepted June 10, 2010.

The formation of differentiated cell types generally requires extracellular cues that culminate in the nucleus to control the sets of genes involved in specialized cellular functions. Recently, it has become apparent that microRNAs (miRNAs) provide an important layer of control to regulatory networks for cell differentiation (Liu and Olson 2010; Zhao et al. 2010). miRNAs are noncoding RNAs $\sim 21$ nucleotides ( $\mathrm{nt}$ ) in length that influence gene expression by inhibiting translation or inducing mRNA degradation. Specific miRNAs are targeted by complementary Watson-Crick base-pairing with sequences in

[Keywords: miR-451; microRNA-451; erythroid differentiation; 14-33ל; ywhaz; antagomir]

${ }^{8}$ Corresponding author.

E-MAIL eric.olson@utsouthwestern.edu; FAX (214) 648-1196.

Article is online at http://www.genesdev.org/cgi/doi/10.1101/gad.1942810 Freely available online through the Genes \& Development Open Access option. the $3^{\prime}$ untranslated region $\left(3^{\prime}\right.$ UTR) of target mRNAs (Ambros 2001).

Erythropoietin (EPO) plays a central role in the process of erythroid differentiation, during which primitive erythroid progenitors differentiate into mature enucleated erythrocytes (Constantinescu et al. 1999). EPO binding to the EPO receptor results in the activation of multiple major signaling cascades. STAT5-dependent transcription of the anti-apoptotic gene Bcl-XL, phosphatidylinositol 3 kinase $(\mathrm{PI} 3 \mathrm{~K})$ regulation of $\mathrm{AKT}$ and the transcription factors GATA1 and Foxo3a, and activation of the Ras/MAPK cascade are essential intracellular mediators of EPOinduced signal transduction (Zhang and Lodish 2007). GATA1, a transcription factor essential for hematopoiesis, regulates the expression of miR-144 and miR-451, which are encoded by a bicistronic transcript expressed selectively in erythroid cells. These miRNAs have been implicated in erythroid differentiation, consistent with the central role of GATA1 in this process (Dore et al. 2008; Fu et al. 2009; Pase et al. 2009; Papapetrou et al. 2010). miR-144 has been suggested to regulate $\alpha$-hemoglobin expression in zebrafish by targeting the erythroid-specific transcription factor KLFD (Fu et al. 2009). Similarly, combined knockdown of miR-144 and miR-451 in mouse bone marrow using an unconventional approach that employs miRNA "decoys" results in abnormal erythroid differentiation, suggesting cooperative regulation of this process by both miRNAs (Papapetrou et al. 2010). Overexpression of miR-451 in the mouse erythroleukemia (MEL) cell line and the human K562 leukemic cell erythroid line results in the induction of erythroid differentiation (Bruchova-Votavova et al. 2010). Similarly, overexpression of miR-451 but not miR-144 in miR-144/451 mutant zebrafish rescues erythropoiesis (Dore et al. 2008; Pase et al. 2009). It has been proposed that miR451 regulates erythrocyte differentiation by repressing GATA2, a pro-stem cell transcription factor (Pase et al. 2009). However, the lack of a miR-451 target sequence within the 3' UTR of GATA2 mRNA in mammals suggests that miR-451 may function by alternate mechanisms. Overall, considerable ambiguity remains as to the role of miR451 in mammalian erythroid differentiation, as well as the potential downstream targets that may mediate its actions.

To investigate the functions of miR-451 in vivo, we generated mice lacking miR-451. $\mathrm{miR}-451^{-/-}$mice display a mild reduction in hematocrit, accompanied by expansion of the colony-forming unit erythroid (CFU-E) progenitor cell population in bone marrow and spleen, as well as a reduced capacity to amplify erythrocyte cell number in response to oxidative stress. Transient inhibition of miR451 in adult mice with an antagomir induces similar defects. miR-451 targets the mRNA encoding 14-3-3 $\zeta$, a chaperone protein that modulates intracellular growth factor signals at multiple steps (Sliva et al. 2000; Barry et al. 2009). Thus, $m i R-451^{-/-}$erythroblasts express $14-3-3 \zeta$ at elevated levels, and inhibition of $14-3-3 \zeta$ rescues their erythroid differentiation defect. Our results identify 14-3$3 \zeta$ as a key target whereby $\mathrm{miR}-451$ regulates erythropoiesis, and provide the first demonstration of an antagomir mimicking the genetic deletion of a miRNA in vivo.

\section{Results and Discussion}

miR-144 and miR-451 are transcribed as a bicistronic transcript that gives rise to the two mature miRNAs (Fig. 1A; 


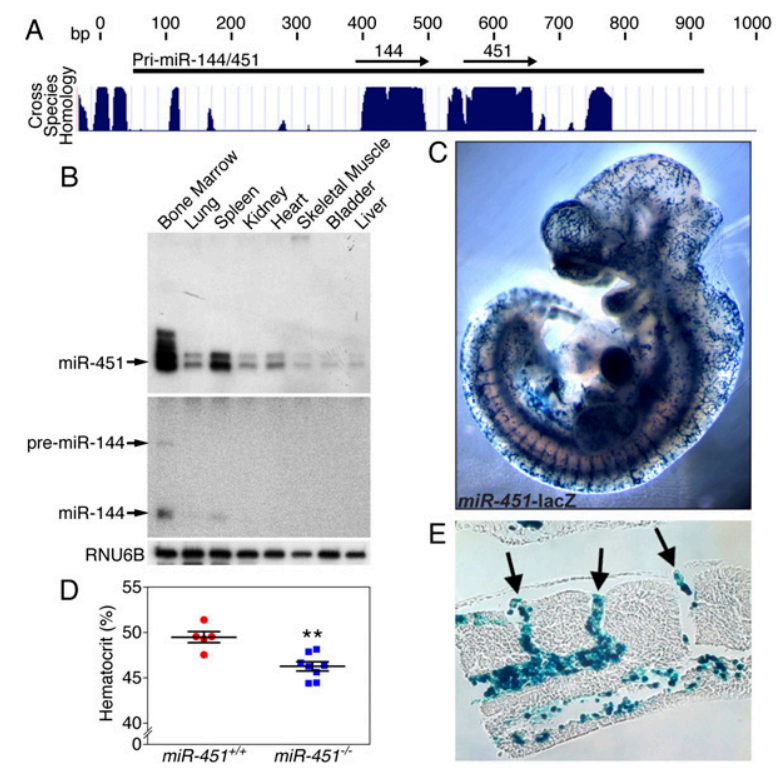

Figure 1. miR-451 is expressed in erythrocytes, and $m i R-451^{-/}$ mice display a reduction in hematocrit. (A) A schematic showing the genomic location of the miR-144/451 transcription unit. Mammalian conservation is represented as a histogram. $(B)$ Northern blot analysis of miR-451 and miR-144 expression across multiple tissues. Pre-miR-144 is denoted with an arrow. Pre-miR-451 is not detected. $(C)$ Expression of $\beta$-gal driven by the miR-451 enhancer is restricted to the circulatory system at $13.5 \mathrm{dpc}$. $(D)$ Hematocrit measurements represented as a dot plot. Data from $\operatorname{miR}-451^{+/+}(n=5)$ and $m i R$ $451^{-/-}(n=8)$ animals are shown as means \pm SEM. $\left({ }^{\star \star}\right) P<0.01 .(E)$ Cross-section through the intersomitic veins reveals $\beta$-gal positivity of circulating erythrocytes.

Dore et al. 2008). miR-451 expression overlaps with that of miR-144, with the highest expression in bone marrow and spleen (Fig. 1B). It is apparent that miR-451 and miR144 exhibit disparate characteristics when analyzed by Northern blot analysis. Recent studies have characterized the unique Dicer-independent biogenesis of miR-451 (Cheloufi et al. 2010; Cifuentes et al. 2010). In this regard, miR-451 migrates as a ladder upon gel electrophoresis, due to multiple 3' termini (Cheloufi et al. 2010).

To further characterize the expression of the miR-144/ 451 locus in vivo, we generated transgenic mice in which $\beta$-galactosidase ( $\beta$-gal) was expressed under the control of a conserved $5-\mathrm{kb}$ promoter/enhancer region containing the previously characterized GATA-binding sites (Supplemental Fig. 1; Dore et al. 2008). Whole-mount analysis revealed $\beta$-gal reporter expression throughout the circulatory system (Fig. 1C). Sections through the intersomitic veins indicate that this expression is due to $\beta$-gal positivity in circulating erythrocytes (Fig. 1E).

To generate miR-451 mutant mice, loxP sites for Cremediated recombination were introduced at both ends of the pre-miR-451 coding region, leaving pre-miR-144 unmodified. The mutation removed 76 base pairs (bp) of genomic DNA encompassing pre-miR-451 (Supplemental Fig. 2A,B). Deletion of miR-451 was confirmed by genomic PCR analysis (Supplemental Fig. 3).

Northern blot analysis of bone marrow harvested from 8 -wk-old mice showed a $50 \%$ reduction in $\mathrm{miR}-451^{+/-}$ animals and the absence of miR-451 in $m i R-451^{-/-}$ animals. miR-144 levels were unchanged across all genotypes (Supplemental Fig. 2C). Real time RT-PCR on fetal liver cells positive for the mature erythrocyte marker TER119 confirmed these results (Supplemental Fig. 2D). $m i R-451^{-1-}$ animals were obtained at predicted Mendelian ratios and displayed no overt abnormalities up to 8 mo of age (Supplemental Table 1). However, we found a mild reduction in hematocrit of adult $m i R-451^{-/-}$mice compared with miR-451 $1^{+/+}$littermates, suggesting an erythrocyte defect (Fig. 1D).

To examine the effect of miR-451 loss of function on erythroid differentiation, livers were isolated from embryos at 14.5 and $16.5 \mathrm{~d}$ post-coitus (dpc) from $\mathrm{miR}-451^{+/-}$ intercrosses. Erythrocyte development was assayed by flow cytometry analysis based on the expression of CD71 and TER119, as described previously (Socolovsky et al. 2001). Fetal liver cells isolated from $m i R-451^{-/-}$embryos showed a significant decrease in the region IV CD71-/ TER $119^{+}$cell population, representing the most mature erythrocytes (Fig. 2A; Supplemental Fig. 3). miR-451 embryos displayed a haploinsufficient phenotype, with $\sim 50 \%$ of wild-type levels of region IV CD $71^{-} /$TER $119^{+}$ cells (Fig. 2B). Haploinsufficient phenotypes are not typically observed in mice heterozygous for other miRNA-null alleles, highlighting the dependence of erythroid differentiation on miR-451 levels.

To determine whether the differentiation defect observed in $\mathrm{miR}-451^{-1-}$ mice reflected an erythroid cellautonomous function of miR-451 versus a disruption of microenvironmental cues within the hematopoietic niche, in vitro differentiation assays were performed on

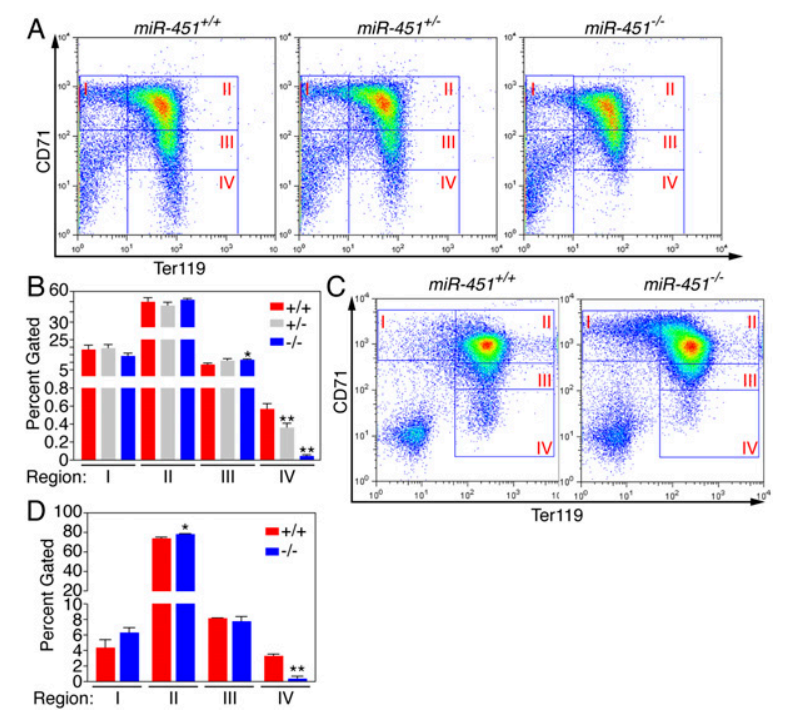

Figure 2. $m i R-451^{-/-}$animals display an embryonic erythroid differentiation defect. (A) FACS analysis of fetal livers harvested from embryos $16.5 \mathrm{dpc}$ and stained for CD71 and TER119. Erythrocytes progress from regions I-IV throughout differentiation, with the most mature erythrocytes represented in region IV. Representative FACS plots from one litter at each time point are shown. $(B)$ Quantitation of percent of cells gated within each region. Data from a representative litter of $\operatorname{miR}-451^{+/+}(n=3), \operatorname{miR}-451^{+/-}(n=4)$, and miR-451 $1^{-1-}(n=2)$ animals are shown as means \pm SEM. $\left({ }^{\star}\right) P<0.05$; $\left({ }^{\star \star}\right) P<0.01$. (C) FACS analysis of in vitro differentiated TER119depleted 14.5-dpc fetal liver $3 \mathrm{~d}$ post-induction by EPO. Cells were stained for CD71 and TER119. Representative FACS plots from one litter are shown. $(D)$ Quantitation of percent of cells gated within

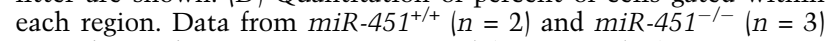
animals are shown as means \pm SEM. $\left(^{\star}\right) P<0.05 ;\left(^{\star \star}\right) P<0.01$. 
$14.5 \mathrm{dpc}$ fetal liver cells as described previously (Zhang et al. 2003). This assay replaces endogenous cues with exogenously supplied growth factors, allowing for standardization of the microenvironment. In vitro differentiation revealed a decrease in the $\mathrm{CD} 71^{-} / \mathrm{TER} 119^{+}$cell population from cell suspensions isolated from $\mathrm{miR}-451^{-/-}$ mice when compared with wild-type littermates, indicating that the differentiation defect observed in vivo is erythrocyte-autonomous (Fig. 2C,D).

To determine the effect of miR-451 ablation on erythrocyte differentiation in adult hematopoietic tissues, flow cytometry analysis was performed. $m i R-451^{-1-}$ animals displayed a reduction in region IV CD $71^{-} /$TER $119^{+}$erythrocytes and a concomitant increase in region $\mathrm{II} \mathrm{CD} 71^{+} /$ TER $119^{+}$erythroblasts in bone marrow (Figs. 3A,B). This defect likely contributes to the observed reduction in the hematocrit of $m i R-451^{-1-}$ animals compared with $m i R$ $451^{+/+}$littermates.

Histologic analysis of spleens isolated from $\mathrm{miR}-451^{+/+}$ and $m i R-451^{-1-}$ animals revealed an increase in cellularity in the mutants with hypercellular clusters of erythroid colonies (Fig. 3C; Supplemental Fig. 5). We measured the number of erythroid progenitors in spleen and bone marrow directly by performing colony-forming assays for burst-forming unit erythroid (BFU-E) and CFU-E progenitors (Fig. 3D). $\mathrm{miR}-451^{-/-}$animals displayed dramatically increased numbers of CFU-E progenitors in bone

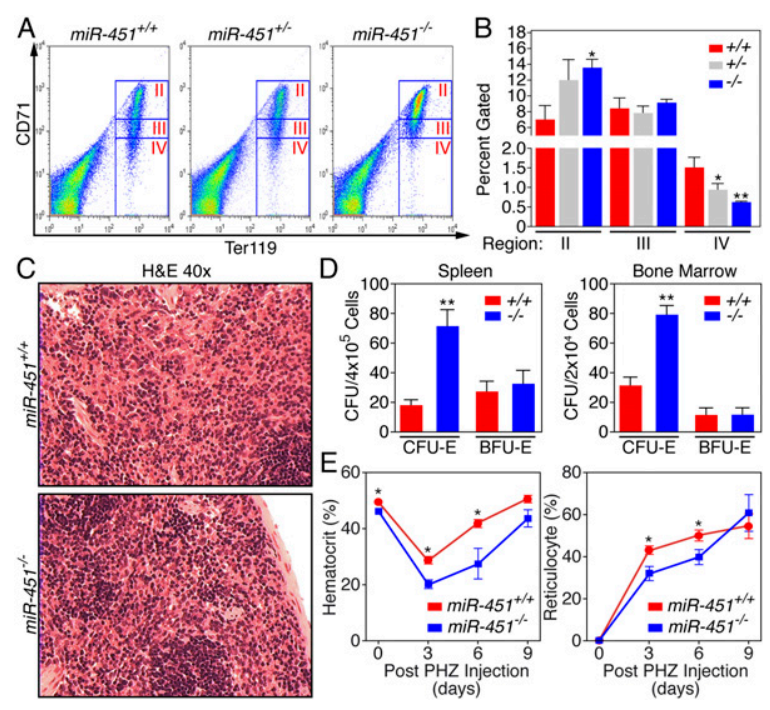

Figure 3. $m i R-451^{-1-}$ mice display an erythroid differentiation defect in adulthood and cannot sustain a high rate of erythropoiesis. (A) FACS analysis of bone marrow harvested from 8-wk-old male littermates stained for CD71 and TER119. Representative FACS plots from one litter are shown. $(B)$ Quantitation of percent of cells gated within each region. Data from $m i R-451^{+/+}(n=3), m i R-451^{+/}$ $(n=5)$, and $m i R-451^{-1-}(n=3)$ animals are shown as means \pm SEM. $\left(^{\star}\right) P<0.05 ;\left(^{\star \star}\right) P<0.01 .(C)$ Hematoxylin and eosin-stained sections of spleens harvested from 8 -wk-old male littermate $m i R-451^{+/+}$and miR- $451^{-/-}$animals. Increased cellularity is observed at $40 \times$ magnification. $(D)$ Colony-formation assays for CFU-E and BFU-E were performed on three independent sets of $m i R-451^{+/+}$and $m i R-451^{-/}$ littermates. Data from a representative set of littermates are displayed, with $n=2$ assays for each animal. Data are shown as means \pm SEM. $\left(^{\star \star}\right) P<0.01$. (E) PHZ was injected in $m i R-451^{-1-}$ and miR-451 $1^{+/+}$animals on days 0,1 , and 3 . Hematocrit values and reticulocyte counts were obtained on days $0,3,6$, and 9. Data from $\mathrm{miR}-451^{+/+}(n=5)$ and $\mathrm{miR}-451^{-/-}(n=8)$ animals are shown as means \pm SEM. $\left(^{*}\right) P<0.05$. marrow and spleen; however, BFU-E progenitors were similar in both $m i R-451^{-/-}$and $m i R-451^{+++}$littermates. Consistent with the expansion of immature erythroid precursors observed by flow cytometry analysis, these data suggest that the erythrocyte differentiation defect results in the expansion of the early erythroblast population. This expansion may be due to the loss of miR-451, or it may reflect a response to increased EPO secretion secondary to an anemic state. Finally, the cell-autonomous differentiation defect observed embryonically and the maintenance of this phenotype throughout adulthood suggest a constitutive need for miR-451 specifically in the process of erythroid differentiation.

A low rate of erythropoiesis is required to maintain a steady-state hematocrit in adult mice compared with embryonic hematopoietic tissue. Therefore, the mild reduction in hematocrit of adult $m i R-451^{-/-}$animals likely reflects the ability of $m i R-451^{-1-}$ hematopoietic tissues to compensate and achieve a steady-state output of erythrocytes. To examine the ability of adult hematopoietic tissues to increase their erythropoietic rate in the absence of $\mathrm{miR}-451$, we subjected $\mathrm{miR}-451^{-/-}$and $\mathrm{miR}-451^{+/+}$ animals to hemolytic anemia by injecting them with phenylhydrazine hydrochloride (PHZ) (Socolovsky et al. 2001). Hematocrit and reticulocyte levels were monitored on days $0,3,6$, and 9 thereafter. The decrease in hematocrit was greater in $m i R-451^{-/-}$animals compared with $\mathrm{miR}-451^{+/+}$littermates, reflecting a hypersensitivity of mutant erythrocytes to PHZ-induced damage. $m i R-451^{-1-}$ animals displayed a delay in recovery (Fig. 3E), indicative of a defect in generating a high erythropoietic rate. These data are consistent with results indicating that miR-451 regulates the erythrocyte response to oxidative stress, and indicate a constitutive requirement for miR451 in the process of erythroid differentiation (Yu et al. 2010).

The erythroid differentiation defect observed in $m i R$ $451^{-/-}$animals could, in principle, result from a developmental insult or the chronic absence of miR-451. To test whether acute inhibition of miR-451 was also sufficient to impede erythroid differentiation, we performed injections of wild-type animals with a cholesterol-modified miR-451 antagomir that inhibits miRNA function by Watson-Crick base-pairing to the mature miRNA (Krutzfeldt et al. 2005). miR-451 antagomir-treated animals displayed a 90\% reduction of miR-451 in bone marrow and complete loss in other tissues (Fig. 4A; Supplemental Fig. 6). Antagomir451-injected animals also displayed an increase in region II CD $71^{+} /$TER $119^{+}$erythroblasts, with a concomitant decrease in region IV CD71- ${ }^{-}$TER $119^{+}$erythrocytes, suggesting that acute inhibition of miR-451 function results in the rapid block of erythrocyte differentiation, as observed in the $\mathrm{miR}-451^{-/-}$animals (Fig. 4B). These data suggest that miR-451 plays a constitutive role in the differentiation of erythrocytes, and that $m i R-451^{-/-}$erythrocytes display this defect due to the chronic requirement for miR-451 rather than an embryonic insult. These findings also demonstrate that chronic versus transient loss of miRNA function has similar consequences. This is the first study concomitantly describing the same phenotype in both miRNA genetic-null animals and animals injected with miRNA inhibitors.

To determine the mechanism of miR-451-mediated erythroid differentiation, we compared gene expression profiles of $\mathrm{CD} 71^{+} / \mathrm{TER} 119^{+}$erythroblasts from $\mathrm{miR}-451^{-/-}$ 
A
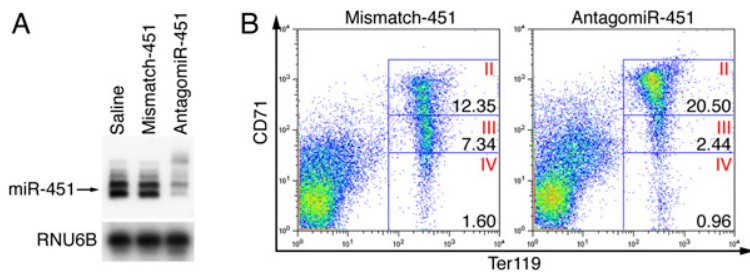

Figure 4. miR-451 inhibition with antagomir-451 rapidly induces a defect in erythroid differentiation. (A) Northern blot analysis of miR-451 in bone marrow of animals injected with either saline, mismatch, or antagomir-451 shows $90 \%$ knockdown of miR-451. $(B)$ FACS analysis was performed on bone marrow stained with CD71 and TER119. Percentage of cells gated are displayed within the respective gate

and $m i R-451^{+/+}$fetal liver cells at 14.5 dpc. miR-451 expression is absent in TER $119^{-}$erythroblasts (Dore et al. 2008). Therefore, the $\mathrm{CD} 71^{+} / \mathrm{TER} 119^{+}$(region II) population was chosen for analysis due to its high expression of miR-451 and its relative uniformity across genotypes at $14.5 \mathrm{dpc}$.

By microarray analysis, we found a total of 130 probe sets that were up-regulated twofold or more and 26 probe sets that were up-regulated threefold or more in $m i R$ $451^{-/-}$cells compared with $\mathrm{miR}-451^{+/+}$cells (Supplemental Table 2). From this list, 13 genes are predicted to be targeted by miR-451 by the target prediction algorithm microCosm (http://www.ebi.ac.uk/enright), whereas only three of these genes are predicted miR-451 targets by the Targetscan algorithm (http://www.targetscan.org), which more stringently considers cross-species conservation. These three genes (ywhaz, cab39, and vapa) contain miR451-binding sites conserved in mammals. Of these genes, ywhaz, which encodes the chaperone protein 14-3-3 $\zeta$, was up-regulated most dramatically. Due to the high conservation of the 3' UTR, the magnitude of up-regulation of ywhaz, and the established role of $14-3-3 \zeta$ as a modulator of hematopoiesis, we hypothesized that ywhaz was primarily responsible for the defect observed in $\mathrm{miR}-451^{-/-}$animals (Stomski et al. 1999; Sliva et al. 2000; Barry et al. 2009). The miR-451 target sequence in ywhaz 3' UTRs is conserved across species (Supplemental Figure 7A). Gene ontology analysis using the database for annotation, visualization, and integrated discovery (DAVID) (Dennis et al. 2003) algorithm revealed perturbations of a variety of cellular processes in $\mathrm{miR}-451^{-/-}$erythroblasts (Supplemental Table 3). Further analysis of the microarray revealed that mRNA levels of the previously published miR-451 target GATA2 were unchanged across genotypes (Supplemental Table 2).

To directly test for possible regulation of ywhaz by miR451, TER $119^{+}$-enriched $14.5 \mathrm{dpc}$ fetal liver cells were harvested from $\mathrm{miR}-451^{-/-}$and $\mathrm{miR}-451^{+/+}$animals, and quantitative real-time RT-PCR for six transcripts encoding 14-3-3 isoforms was performed. Of these transcripts, only ywhaz was up-regulated in $\mathrm{miR}-451^{-1-}$ cells compared with $\mathrm{miR}-451^{+/+}$cells (Supplemental Fig. 7B). Immunoblot analysis revealed $\sim 1$.5-fold up-regulation of $14-3-3 \zeta$ protein levels in $\mathrm{miR}-451^{+/-}$cells and twofold up-regulation in miR-451 $1^{-1-}$ cells (Fig. 5A,B). A luciferase reporter fused to the ywhaz 3' UTR was repressed by miR-451 in COS-1 cells, and mutation of the miR-451-binding site within this UTR abolished repression by miR-451 (Fig. 5C).

14-3-3 chaperone proteins play important roles in the assembly of signaling complexes required for the coordinate activation of pathways downstream from growth factor receptors. These proteins bind phosphoserine/threonine-containing sequences, and thereby modulate protein-protein interactions and subcellular localization of their targets (Aitken 2006). Numerous studies have implicated 14-3-3 $\zeta$ in signaling and transcriptional events involved in hematopoiesis (Stomski et al. 1999; Barry et al.

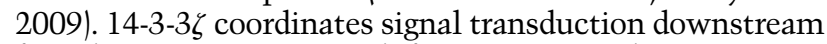
from hematopoietic growth factor receptors by interacting with the common signaling subunit of the granulocytemacrophage colony-stimulating factor (GM-CSF), interleukin 3 (IL-3), and IL-5 receptors (Stomski et al. 1999), and interacts directly with the IL-9 receptor (Sliva et al. 2000). 14-3-3 $\zeta$ also governs PI3K signaling downstream from GMCSF, a key regulator of erythropoiesis (Barry et al. 2009), and association of 14-3-3 with Gab2, a docking protein required for hematopoiesis, terminates Gab2 function (Brummer et al. 2008).

Due to the role of $14-3-3 \zeta$ as a regulator of hematopoiesis, we hypothesized that repression of 14-3-3 $\zeta$ expression

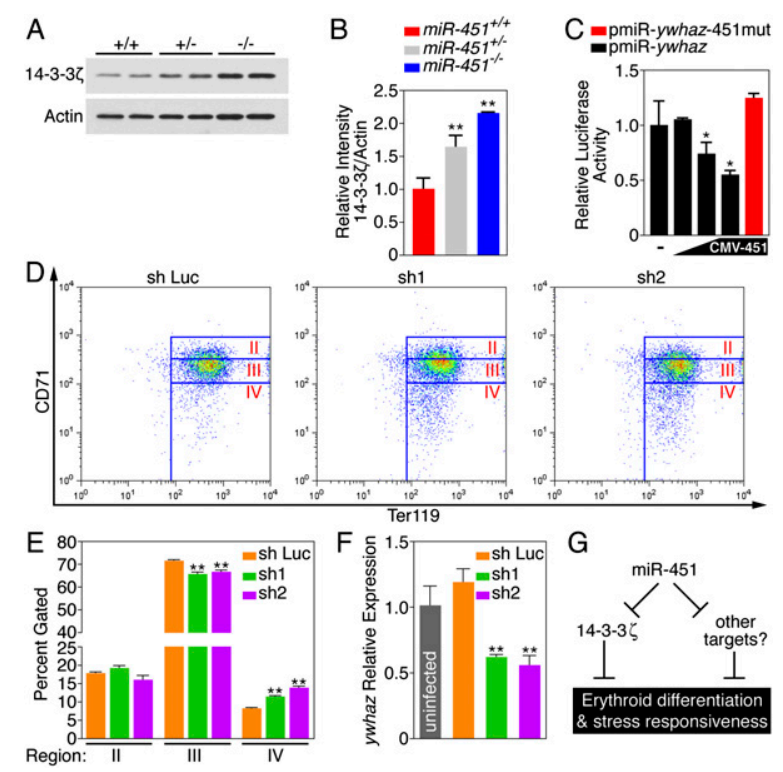

Figure 5. miR-451 repression of $14-3-3 \zeta$ regulates erythroid differentiation. $(A)$ Immunoblot analysis for $14-3-3 \zeta$ on protein harvested from $14.5 \mathrm{dpc}$ fetal liver TER $119^{+}$erythrocytes. Two individual animals from each genotype were run in adjacent lanes. $(B)$ Densitometry analysis of the immunoblot shown in $A$. Data are shown as means \pm SEM. $\left.{ }^{\star \star}{ }^{\star}\right) P<0.01$. (C) A luciferase reporter construct fused to the ywhaz 3' UTR is repressed by miR-451 in a dose-dependent manner. Mutation of this binding site abolishes miR-451-mediated repression. Data from $n=3$ per condition are shown as means \pm SEM. $\left(^{\star}\right) P<0.05$. (D) FACS analysis of in vitro differentiated TER119-depleted 14.5-dpc $m i R-451^{-/-}$fetal liver cells 3 d postinduction by EPO. Cells shown are GFP-positive, representing viability and expression of one of two shRNAs targeted against 14$3-3 \zeta$ (sh-1 and sh-2) or against Luciferase (sh-Luc) as a control. Cells were stained for CD71 and TER119. Representative FACS plots from each condition are shown. $(E)$ Quantitation of percent of cells gated within each individual region. Data from $n=3$ per condition are shown as means \pm SEM. $\left(^{*}\right) P<0.05 ;\left(^{\star \star}\right) P<0.01$. $(F)$ Real-time RTPCR analysis of ywhaz expression from in vitro differntiation assays represented in $D$. Reactions were peformed on cDNA reversetranscribed from RNA harvested from whole-cell suspensions $\left(\mathrm{GFP}^{-}\right.$ and $\mathrm{GFP}^{+}$cells). (G) Schematic representation of the role of $\mathrm{miR}-451$ as a regulator of $14-3-3 \zeta$, erythroid differentiation, and the response of erythrocytes to stress. 
in $\operatorname{miR}-451^{-/-}$erythrocytes would relieve the erythroid differentiation defect. To test this hypothesis, we infected 14.5-dpc TER119- progenitor-rich fetal liver cells with shRNAs targeting two separate regions of the ywhaz transcript, abbreviated sh-1 and sh-2, using retroviral vectors. A retrovirus expressing a shRNA directed against luciferase (sh-Luc) was used as a control. Due to the reproducible differentiation defect observed ex vivo, we used our in vitro differentiation system to assay for functional rescue of the erythroid differentiation defect observed in $m i R-451^{-/-}$animals. Expression of GFP from an internal ribosomal entry site (IRES) allowed for the identification of viable infected cells throughout differentiation. Each shRNA directed against 14-3-3 $\zeta$ efficiently reduced its expression (Supplemental Fig. 8). Pooled fetal liver cells from 14.5-dpc embryos isolated from $m i R-451^{-1-}$ intercrosses were first depleted of TER $119^{+}$cells by MACS, separated into individual wells, and then infected with retrovirus expressing either sh-1, sh-2, or sh-Luc. Cells were then resuspended in medium containing EPO and induced to differentiate as described previously (Zhang et al. 2003). Knockdown of ywhaz was confirmed from total cell suspensions (GFP-positive and GFP-negative cells) isolated at the time of flow cytometry analysis (Fig. 5F). Due to contaminating uninfected GFPnegative cells, this knockdown efficiency is likely an underestimation of functional 14-3-3 $\zeta$ knockdown in GFP-positive cells. On day 3, a differentiation defect was clearly observed in $m i R-451^{-1-}$ GFP-positive cells infected with sh-Luc; however, cells infected with sh-1 or sh-2 displayed an increase in CD71-/TER $119^{+}$cells (Fig. $5 \mathrm{D}, \mathrm{E})$. This shift was observed in both shRNA-treated groups and not in the sh-Luc-infected group, indicating an increase in erythroid differentiation due to the specific repression of $14-3-3 \zeta$. These data demonstrate that repression of 14-3-3 $\zeta$ enhances erythroid differentiation in the absence of miR-451, and strongly supports the conclusion that miR-451 repression of $14-3-3 \zeta$ enhances erythroid differentiation.

Loss of function and gain of function of specific effectors downstream from the EPO receptor typically result in erythrocyte defects (Zhang and Lodish 2007). Loss of K-ras diminishes AKT activation, and thereby results in a mild erythroid differentiation defect (Zhang and Lodish 2005). Conversely, overexpression of factors that exaggerate intracellular signaling similarly induce erythroid differentiation defects. Chronic activation of STAT5, AKT, and p44/42 MAPK in erythroid progenitors by K-ras expression leads to a mild block in terminal erythroid differentiation, and expansion of erythroid progenitors (Zhang et al. 2007). Hyperactivation of these pathways blocks terminal erythroid differentiation and leads to cytokine-independent growth of erythroid progenitors (Braun et al. 2004). Due to the essential function of $14-3-3 \zeta$ as an effector of PI3K/AKT pathways, it is likely that its misregulation in erythroid progenitors affects the differentiation process. Finally, our finding that inhibition of $14-3-3 \zeta$ in $m i R-451^{-/-}$animals restores erythroid differentiation suggests that $14-3-3 \zeta$ is a key downstream effector of the proerythroid actions of this miRNA.

Our results indicating the sensitization of $\mathrm{miR}-451^{-/-}$ erythrocytes to oxidative stress are consistent with work indicating a similar phenotype in $\mathrm{miR}-144^{-/} / \mathrm{miR}-451^{-/-}$ animals, and suggest that miR-451 rather than miR-144 regulates this process (Yu et al. 2010). Yu et al. (2010), however, did not observe an erythrocyte differentiation defect in adult hematopoietic tissues. It is possible that this discrepancy is due to the combined knockout of both miR-144 and miR-451. miR-144 has been shown to influence hemoglobin expression; therefore, loss of miR-144 and its effects on hemoglobin may result in the activation of compensatory pathways, blunting the differentiation defect (Fu et al. 2009). To address this possibility, a miR144 loss-of-function model should be analyzed.

Our findings that red blood cell production shows a stoichiometric dependency on miR-451 levels, and that acute inhibition of miR-451 with an antagomir induces an erythroid differentiation defect, suggest that miR-451 oligonucleotide inhibitors may be efficacious in the treatment of red cell dyscrasias, such as polycythemia vera, or other hematopoietic malignancies. Finally, miR451 has been reported to participate in other disorders, including glioma tumorigenesis and pulmonary hypertension (Caruso et al. 2010; Godlewski et al. 2010). Thus, it will be of interest to determine whether inhibitor miR451 oligonucleotides demonstrate therapeutic efficacy in these disorders.

\section{Materials and methods}

Generation of miR-451 mutant mice

pre-miR-451 was targeted by homologous recombination in embryonic stem cells. Chimeric mice were bred to C57BL/6 mice. A detailed description of miR-451 mutant generation is provided in the Supplemental Material.

\section{Hematocrit and reticulcyte measurements}

Hematocrit was measured using a hematocrit centrifuge. Reticulocytes were counted using the Miller Disc method. Details are provided in the Supplemental Material.

\section{FACS, cell purification, and in vitro differentiation assays}

Cells were analyzed by FACS analysis as described in the Supplemental Material. Cell purification was performed by the Flow Cytometry Core Facility (University of Texas Southwestern). MACS was performed through MACS separation columns (Miltenyi Biotec). Differentiation assays were performed as described previously (Zhang et al. 2003). Details are provided in the Supplemental Material.

\section{Antagomir injections}

Antagomir or scrambled control $(80 \mathrm{mg} / \mathrm{kg})$ was injected on days 0 and 1 , and mice were analyzed on day 3 .

\section{Microarray analysis}

RNA harvested from TER $119^{+} / \mathrm{CD} 71^{+}$cells was analyzed using Mouse Genome 430 A2.0 chips (Affymetrix). Details of analyses are provided in the Supplemental Material.

Experimental procedures are described in detail in the Supplemental Material.

\section{Acknowledgments}

We are grateful to Mitchell Weiss for helpful discussions and sharing of unpublished data. We also thank Mitchell Weiss, Yu Yao, and Guowei Zhao for providing viruses and the Western blot shown in Supplemental Figure 7. We thank Angela Mobley and the University of Texas Southwestern Flow 
Cytometry Core Facility, the University of Texas Southwestern Microarray Core Facility, and Anna E. Patrick for technical assistance. We gratefully acknowledge miRagen Therapeutics and Eva van Rooij for providing miR451 antagomirs. We also thank Mei Xin, Daniel Quiat, and Eric Small for careful reading of the manuscript. This work was supported by grants to E.N.O. from the NIH, the Robert A. Welch Foundation, and the American Heart Association-Jon Holden DeHaan Foundation; a grant to L.J.H. from the NIH (HL089966); and a grant to D.M.P. from the NIH (HL09530601A1).

\section{References}

Aitken A. 2006. 14-3-3 proteins: A historic overview. Semin Cancer Biol 16: $162-172$.

Ambros V. 2001. MicroRNAs: Tiny regulators with great potential. Cell 107: 823-826.

Barry EF, Felquer FA, Powell JA, Biggs L, Stomski FC, Urbani A, Ramshaw H, Hoffmann P, Wilce MC, Grimbaldeston MA, et al. 2009. 14-3-3:Shc scaffolds integrate phosphoserine and phosphotyrosine signaling to regulate phosphatidylinositol 3-kinase activation and cell survival. J Biol Chem 284: 12080-12090.

Braun BS, Tuveson DA, Kong N, Le DT, Kogan SC, Rozmus J, Le Beau MM, Jacks TE, Shannon KM. 2004. Somatic activation of oncogenic Kras in hematopoietic cells initiates a rapidly fatal myeloproliferative disorder. Proc Nat1 Acad Sci 101: 597-602.

Bruchova-Votavova H, Yoon D, Prchal JT. 2010. miR-451 enhances erythroid differentiation in K562 cells. Leuk Lymphoma 51: 686-693.

Brummer T, Larance M, Herrera Abreu MT, Lyons RJ, Timpson P, Emmerich CH, Fleuren ED, Lehrbach GM, Schramek D, Guilhaus M, et al. 2008. Phosphorylation-dependent binding of 14-3-3 terminates signalling by the Gab2 docking protein. EMBO I 27: 2305-2316.

Caruso P, MacLean MR, Khanin R, McClure J, Soon E, Southgate M, MacDonald RA, Greig JA, Robertson KE, Masson R, et al. 2010. Dynamic changes in lung microRNA profiles during the development of pulmonary hypertension due to chronic hypoxia and monocrotaline. Arterioscler Thromb Vasc Biol 30: 716-723.

Cheloufi S, Dos Santos CO, Chong MM, Hannon GJ. 2010. A dicerindependent miRNA biogenesis pathway that requires Ago catalysis. Nature 465: 584-589.

Cifuentes D, Xue H, Taylor DW, Patnode H, Mishima Y, Cheloufi S, Ma E, Mane S, Hannon GJ, Lawson N, et al. 2010. A novel miRNA processing pathway independent of dicer requires Argonaute2 catalytic activity. Science 328: 1694-1698.

Constantinescu SN, Ghaffari S, Lodish HF. 1999. The erythropoietin receptor: Structure, activation and intracellular signal transduction. Trends Endocrinol Metab 10: 18-23.

Dennis G Jr, Sherman BT, Hosack DA, Yang J, Gao W, Lane HC, Lempicki RA. 2003. DAVID: Database for annotation, visualization, and integrated discovery. Genome Biol 4: 3. doi: 1186/gb-2003-4-5-p3.

Dore LC, Amigo JD, Dos Santos CO, Zhang Z, Gai X, Tobias JW, Yu D, Klein AM, Dorman C, Wu W, et al. 2008. A GATA-1-regulated microRNA locus essential for erythropoiesis. Proc Natl Acad Sci 105: 3333-3338.

Fu YF, Du TT, Dong M, Zhu KY, Jing CB, Zhang Y, Wang L, Fan HB, Chen Y, Jin Y, et al. 2009. mir-144 selectively regulates embryonic $\alpha$-hemoglobin synthesis during primitive erythropoiesis. Blood 113: 1340-1349.

Godlewski J, Nowicki MO, Bronisz A, Nuovo G, Palatini J, De Lay M, Van Brocklyn J, Ostrowski MC, Chiocca EA, Lawler SE. 2010. MicroRNA-451 regulates LKB1/AMPK signaling and allows adaptation to metabolic stress in glioma cells. Mol Cell 37: 620-632.

Krutzfeldt J, Rajewsky N, Braich R, Rajeev KG, Tuschl T, Manoharan M, Stoffel M. 2005. Silencing of microRNAs in vivo with 'antagomirs.' Nature 438: 685-689.

Liu N, Olson EN. 2010. MicroRNA regulatory networks in cardiovascular development. Dev Cell 18: 510-525.

Papapetrou EP, Korkola JE, Sadelain M. 2010. A genetic strategy for single and combinatorial analysis of miRNA function in mammalian hematopoietic stem cells. Stem Cells 28: 287-296.

Pase L, Layton JE, Kloosterman WP, Carradice D, Waterhouse PM, Lieschke GJ. 2009. miR-451 regulates zebrafish erythroid maturation in vivo via its target gata2. Blood 113: 1794-1804.

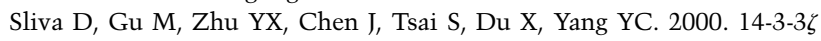
interacts with the $\alpha$-chain of human interleukin 9 receptor. Biochem $J$ 345: $741-747$.
Socolovsky M, Nam H, Fleming MD, Haase VH, Brugnara C, Lodish HF. 2001. Ineffective erythropoiesis in Stat $5 \mathrm{a}^{-1-} 5 \mathrm{~b}^{-/-}$mice due to decreased survival of early erythroblasts. Blood 98: 3261-3273.

Stomski FC, Dottore M, Winnall W, Guthridge MA, Woodcock J, Bagley CJ, Thomas DT, Andrews RK, Berndt MC, Lopez AF. 1999. Identification of a 14-3-3 binding sequence in the common $\beta$ chain of the granulocyte-macrophage colony-stimulating factor (GM-CSF), interleukin-3 (IL-3), and IL-5 receptors that is serine-phosphorylated by GM-CSF. Blood 94: 1933-1942.

Yu D, dos Santos CO, Zhao G, Jiang J, Amigo JD, Khandros E, Dore LC, Yao Y, D'Souza J, Zhang Z, et al. 2010. miR-451 protects against erythroid oxidant stress by repressing 14-3-3\%. Genes Dev (this issue). doi: $10.1101 /$ gad.1942110.

Zhang J, Lodish HF. 2005. Identification of K-ras as the major regulator for cytokine-dependent Akt activation in erythroid progenitors in vivo. Proc Natl Acad Sci 102: 14605-14610.

Zhang J, Lodish HF. 2007. Endogenous K-ras signaling in erythroid differentiation. Cell Cycle 6: 1970-1973.

Zhang J, Socolovsky M, Gross AW, Lodish HF. 2003. Role of Ras signaling in erythroid differentiation of mouse fetal liver cells: Functional analysis by a flow cytometry-based novel culture system. Blood 102: 3938-3946.

Zhang J, Liu Y, Beard C, Tuveson DA, Jaenisch R, Jacks TE, Lodish HF. 2007. Expression of oncogenic K-ras from its endogenous promoter leads to a partial block of erythroid differentiation and hyperactivation of cytokine-dependent signaling pathways. Blood 109: 52385241.

Zhao G, Yu D, Weiss MJ. 2010. MicroRNAs in erythropoiesis. Curr Opin Hematol 17: 155-162. 


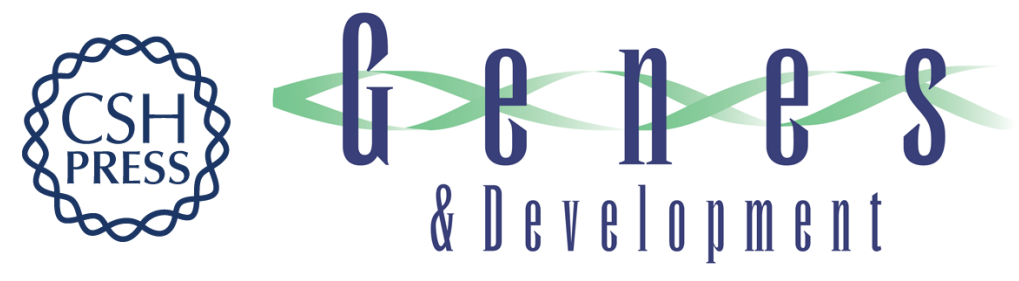

\section{Defective erythroid differentiation in miR-451 mutant mice mediated by 14-3-3 $\zeta$}

David M. Patrick, Cheng C. Zhang, Ye Tao, et al.

Genes Dev. 2010, 24:

Access the most recent version at doi:10.1101/gad.1942810

\section{Supplemental http://genesdev.cshlp.org/content/suppl/2010/07/26/24.15.1614.DC1 \\ Material}

Related Content

References

This article cites 26 articles, 13 of which can be accessed free at:

http://genesdev.cshlp.org/content/24/15/1614.full.html\#ref-list-1

Articles cited in:

http://genesdev.cshlp.org/content/24/15/1614.full.html\#related-urls

License Freely available online through the Genes \& Development Open Access option.

Email Alerting Receive free email alerts when new articles cite this article - sign up in the box at the top Service right corner of the article or click here.

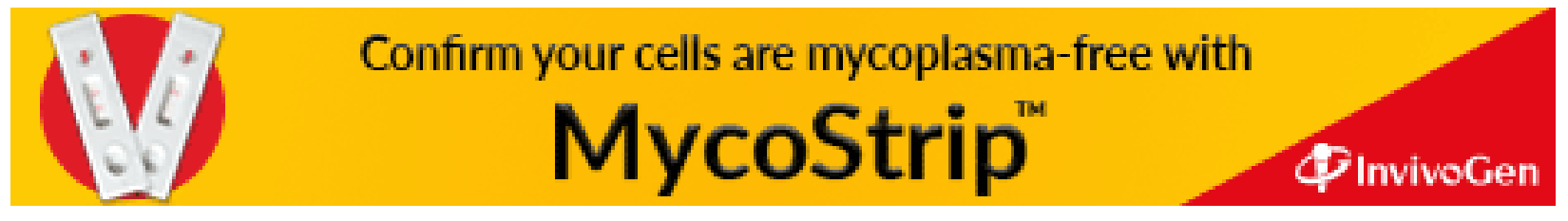

